\title{
Virtual Sex Ed: Youth, Race, Sex, and New Media
}

\author{
Melissa Gilliam • Claire Brindis
}

Published online: 22 February 2011

(C) The Author(s) 2011. This article is published with open access at Springerlink.com

\begin{abstract}
This article is an introduction to the special issue of Sexuality Research and Social Policy, in which we give an overview and highlight the important themes covered by the featured articles. Each paper is based on a presentation given at an interdisciplinary conference, Virtual Sex Ed: Youth, Race, Sex, and New Media, hosted by the Section of Family Planning and Contraceptive Research within the Department of Obstetrics and Gynecology, and the Center for the Study of Race, Politics and Culture at the University of Chicago on June 4, 2009. Given both the reach and the newness of the field, research and analyses will be key to a greater understanding of how to best incorporate technology in our efforts to improve the health and well-being of adolescents.
\end{abstract}

Keywords Adolescent - Digital media - Sex education . Technology $\cdot$ Communication $\cdot$ Social networking

This special issue of Sexuality Research and Social Policy features a series of papers that were presented at the conference Virtual Sex Ed: Youth, Race, Sex, and New

\footnotetext{
M. Gilliam $(\bowtie)$

Department of Obstetrics and Gynecology, University of Chicago, 5841 S. Maryland Ave, MC2050,

Chicago, IL 60637, USA

e-mail: mgilliam@babies.bsd.uchicago.edu

C. Brindis

Philip R. Lee Institute for Health Policy Studies,

Bixby Center for Global Reproductive Health,

National Health Information and Innovation Center,

University of California,

3333 California Street, Suite 265,

San Francisco, CA, USA
}

Media, hosted by the Section of Family Planning and Contraceptive Research within the Department of Obstetrics and Gynecology, and the Center for the Study of Race, Politics and Culture at the University of Chicago on June 4, 2009. Consistent with other conferences in this series, we issued a national call for papers and invited two keynote speakers working at the cutting edge of the field. Conference participants came from diverse scholarly disciplines, including the social sciences, education, and health. Presenters were also drawn from those actively working with youth and digital media.

For the purposes of the conference, we used the term digital media to signify the range of activities in which youth engage, including, but not limited to the Internet, mobile phones, or games. Yet, this term is in no way meant to be static, and we acknowledge that this field is constantly evolving, such that our conference captured a moment in time. Indeed, modalities featured here, such as Myspace, are no longer as prominent as they were at the time of the research. Yet, the lessons learned are lasting. Thus, in this issue, we aim to advance our evolving understanding of a phenomenon which is likely to continue to have rippling effects throughout society. In this "brave new world," research and analyses will be key to a greater understanding of how to best incorporate technology in our efforts to improve the health and wellbeing of adolescents.

We consider how digital media can be used to gain knowledge, to communicate, and/or as a means of self expression. These diverse roles for digital media, in turn, create exciting opportunities for further understanding youth's sexual behavior and also promoting youth's sexual health. 
The conference sought to address some key questions:

- How are youth, especially youth of color, using new media in relationship to sexuality and health information?

- How is new media being used to improve youth's sexual and reproductive health?

- Can digital media reduce existing inequities associated with race and class in sexual health among youth?

Scholars and practitioners presented a range of studies demonstrating the many ways in which youth interact with digital media and its implications for sexual health.

The keynote address by C.J. Pascoe, "Resource and Risk: Youth Sexuality and New Media Use" (2011), sets the stage for this group of articles by describing from a teen's perspective how teens use new media. This paper describes the author's work on the Digital Youth Project, an ethnographic research project funded by the John D and Catherine T MacArthur Foundation, describing youth's informal learning with digital media. This article draws upon a larger project of ethnographic research in which this researcher participated: the Digital Youth Project was a 3-year ethnographic research project conducted from 2005 through 2008 (Ito et al. 2009). ${ }^{1}$ The manuscript presented here integrates ethnographic research into a larger discussion of the literature on sexuality, risk, resources, and health. Pascoe presents striking examples of the way in which youth interact with new media. Youth move seamlessly from a face-to-face encounter to digital communication, arranging meetings and providing a synopsis of the encounter once it is over. Thus, digital media is integrated into relationships as youth "meet, flirt, 'go out,' and break up in both mediated and non-mediated spaces" (Pascoe 2011). Pascoe notes that while most teens meet offline and then continue the relationship online, the Internet may enable marginalized teens to meet youth similar to themselves. Online activities offer teens new freedom of communication as they increase the sphere of private communication, modalities for communication, and the amount of time they devote to communication.

Pascoe also lays the groundwork for understanding the role of the internet in youth sexuality education, contrasting the lack of sexuality education in schools with the potential for sexuality information out of school. While she demonstrates that youth are savvy about whom they befriend or "believe" online, Pascoe cautions that existing offline inequalities mediated by class, race, gender, and sexual identity can be perpetuated online due to lack of home internet access, limited minutes on cell phones, or bullying with a wider audience. Thus, the inequalities and online risks for youth might be more nuanced than previously imagined.

$\overline{{ }^{1} \text { http://digitalyouth.ischool.berkeley.edu/ }}$
The second keynote speaker, Deborah Levine, MA, Executive Director of Internet Sexuality Information Services (ISIS-inc), ${ }^{2}$ provides an overview of digital technology. Much like Pascoe, her paper entitled "Using Technology, New Media, and Mobile for Sexual and Reproductive Health" (2011) describes how closely digital media is integrated into lives of youth. From computer applications (apps), to video sharing, to games, Wikipedia, and podcasts, Levine demonstrates the breadth of digital media and the ways that these different modalities are being used for health promotion. She also provides a number of specific examples of health promotion campaigns, websites, and user-generated content. Moreover, this article serves as a primer for adults interested in engaging youth in health promotion and behavior change. While arguing that digital media is not a tool, but an integrated part of young people's lives, Levine points to potential limits of digital media for health promotion: the perception of risk, the inauthentic voice introduced by adults, and the potential for incorrect or "unmoderated" content. These themes are elaborated upon in subsequent papers.

Health-seeking behaviors of youth are treated in depth in Jones and Biddlecom's article entitled "Is the Internet filling the sexual health information gap for teens?" (2011). Here, the researchers consider the myriad ways in which youth obtain sexual health and contraceptive information, whether digitally or through face-to-face communication. This study of a racially diverse group of students in Indiana and New York provides needed information on youth of color and use of the Internet for sexual health information. Jones finds that youth in her sample were unlikely to use the Internet for sexual health and contraceptive information. Reflecting larger societal concerns about the risk posed by exposure to sexually explicit material on the Internet, youth described the Web as providing untrustworthy information. Youth report a wide range of sources of contraceptive information obtained through informal sources (e.g., family and friends), traditional media (television and advertisements), and formal sources, such as doctors. The "digital divide" does not cause these behaviors; rather, youth in this study consider themselves to be discerning consumers of health information, trusting known, face-to-face sources over unknown Internet sources.

In "Finding Youth in their Space: Using Social Networking Sites to Connect Youth to Sexual Health Services," Ralph et al. (2011) present the first of several articles included in this volume examining the potential for digital media to inform health information interventions. This study considers statewide efforts at reducing teen pregnancy in California and the clinical venues currently using social networking sites to provide teens with confidential

\footnotetext{
2 http://www.isis-inc.org/
} 
information and help them find services. By addressing the potential of social networking sites as a clinical tool from both the patient and clinician perspective, this article provides insights into strengths, weaknesses, and limitations to this approach. Overall, they found that youth of diverse racial and ethnic groups are highly engaged with social networking sites. Yet, youth raise concerns about privacy, preference for social uses, and preference for receiving health information through other sources. With the electronic footprint created by "friending," a clinical site posed a problem for many youth due to potential loss of privacy. Clinic staff cite lack of skills to create social sites and the resistance of clinic administration. Strengths of this approach include the ability to reach large numbers of youth, private interactions, and the complementary and reinforcing nature of the clinic visit and the social network.

In "Improving Low-Income Teen Health Behaviors with Internet-Linked Clinic Interventions," Howard et al. (2011) provide an example of a robust clinic-based health promotion intervention and evaluation. They describe identifying the need to make better use of the time that youth spent in the waiting room and the need to find a way to stem the high rates of sexually transmitted infections among the low-income youth in Atlanta who comprise the clinic's patient population. The detailed description of the formative stages that the leadership of this university-based adolescent clinic embarked on provides helpful information for others to replicate their approach. This article is particularly valuable as the authors evaluate the final interventions by randomizing girls to treatment conditions of self-directed searching of websites compared to a short PowerPoint and then linking to identified "high quality" health information sites.

The final article, "The Enigmatic Messages of Sexuality Education: Julie Gustafson's Desire," advances our understanding of the potential role of digital media in research (Sandlos 2011). Sandlos analyzes documentary film to ask larger questions about how adolescents interpret abstinence and the discourse on adolescent sexuality. She considers how low-income youths negotiate the competing elements of self, family, school, and community. Documentaries of adolescents are used to prompt conversations with adolescents about these issues. Sandlos makes explicit the suggestion that is implicit in all of the articles in this edition: digital media has the ability to turn the tables on the adult-child relationship by providing youth with an opportunity for independence, private exploration, and authorship. Thus, digital media can undermine the typical pedagogical relationship regarding sexuality education. Sandlos argues for a new framework in which sexuality is no longer a "problem to be solved by education." Instead, she suggests that sexuality, with its complexity and emotion, lies within education and that adults may have to take a new approach - one of listening, not necessarily of the "all-knowing guide."

This framing suggests that in the context of digital media, both youth and adults will be presented with new ways of learning. Adults may not automatically assume the leadership role and instead may be forced to observe and guide, rather than transmit information. This concept brings us full circle to CJ Pascoe's description of one youth's ability to communicate with a boyfriend that she is forbidden to have as she is more technologically sophisticated than her parents.

The questions raised by Sandlos and other authors demonstrate that this field is in its nascent stages. Similarly, despite the strong studies presented here, research on sexuality and digital media is also in its infancy.

Both adults and youth will benefit from understanding the strengths and limitations in using digital technology for sexual health promotion. As health and other professionals seek to assure that digital media strategies are used to educate and reinforce educational messages, they too are undergoing a rapid transformation in learning how to channel technologies' utility. For youth, given the increasing role of technology in their lives, we also need to provide opportunities for supportive "human" interactions, where they engage with adults who they trust to help them navigate successfully into adulthood. In an era of "high tech," there continues to be a need for "high touch."

The growing body of evidence regarding the utility of technology in serving and engaging adolescents in an era of shared decision making will be particularly important as different stakeholders - from policymakers to program managers - face the Solomonesque decisions of what strategies are worthy of investment, given limited resources and the rapid nature of technological change.

Thus, we end this issue by including a roundtable discussion to consider the current status of research on digital media in sexuality and health. The articles and conference presentations suggest the many ways that adults, who are interested in the health of youth, approach this topic. Clearly, if the field of technology and health is to advance, we will need new ways of studying these programs and projects to consider which ones show the greatest promise, for whom, and under what circumstances. Roundtable participants are experts in the field of technology-based health promotion, adolescent health, health behavior, and promotion and research evaluation. These individuals considered questions such as: are we at a new frontier? What is the potential for behavior change? And, how do we study and measure technology-based education? These thoughts should provide a strong foundation for establishing a research agenda for this field. 
Open Access This article is distributed under the terms of the Creative Commons Attribution Noncommercial License which permits any noncommercial use, distribution, and reproduction in any medium, provided the original author(s) and source are credited.

\section{References}

Howard, M.N., Davis, J.A., Mitchell, M.E. (2011). Improving lowincome teen health behaviors with internet-linked clinic interventions. Sexuality Research and Social Policy, 8(1) doi:10.1007/ s13178-011-0037-2.

Ito, M., Baumer, S., Bittanti, M., boyd, d, Cody, R., HerrStephenson, B., et al. (2009). Hanging out, messing around, and geeking out: Kids living and learning with new media. Cambridge: MIT Press.
Jones, R., \& Biddlecom, A. (2011). The more things change...: the relative importance of the internet as a source of contraceptive information for teens. Sexuality Research and Social Policy, 8(1) doi:10.1007/s13178-011-0039-0.

Levine, D. (2011). Using technology, new media, and mobile for sexual and reproductive health. Sexuality Research and Social Policy, 8(1) doi:10.1007/s13178-011-0040-7.

Pascoe, C.J. (2011). Resource and risk: youth sexuality and new media use. Sexuality Research and Social Policy. 8(1) doi:10.1007/s13178-011-0042-5.

Ralph, L., Berglas, N., Schwartz, S., Brindis, C. (2011). Finding teens in their space: using social networking sites to connect youth to sexual health services. Sexuality Research and Social Policy, 8(1) doi:10.1007/s13178-011-0043-4.

Sandlos, K. (2011). The enigmatic messages of sexuality education: Julie Gustafson's desire. Sexuality Research and Social Policy, 8(1) doi:10.1007/s13178-011-0041-6. 